\title{
Correction to: Towards Intelligent Interactive Theatre: Drama Management as a Way of Handling Performance
}

Nic Velissaris (D) and Jessica Rivera-Villicana (D)

\section{Correction to:}

Chapter "Towards Intelligent Interactive Theatre: Drama Management as a Way of Handling Performance"

in: R. E. Cardona-Rivera et al. (Eds.): Interactive Storytelling, LNCS 11869, https://doi.org/10.1007/978-3-030-33894-7_24

The original version of this chapter was revised. The incorrectly added affiliation "Applied Artificial Intelligence Institute, Deakin University, Burwood, Australia" of the unaffiliated author "Nic Velissaris" was removed. 